\title{
Víctor Brangier. Saber hacer y decir en justicia. Culturas jurídico-judiciales en la zona centro-sur de Chile (1824-1875), Rosario, Prohistoria, 2019, 211 págs.
}

La renovación del campo de estudios sobre historia social de la justicia puede ser considerada como una perspectiva ya visibilizada en la historiografía latinoamericana. Prólogos, introducciones de libros y artículos académicos han referido, a lo largo de estos últimos veinte años, sobre la pertinencia de las investigaciones ocupadas en relativizar la función de las instituciones legales y de seguridad como un ejercicio vertical de control social. En simultáneo, han rescatado los abordajes que se ocupan de analizar los usos sociales de la justicia, concibiendo el espacio judicial como un ámbito conflictivo de negociaciones y acuerdos (Salvatore, Aguirre \& Joseph, 2001). A pesar de ello, todavía restan estudios que concreten las promesas de dicho proyecto historiográfico, observando la manera en que dichos intercambios de desarrollan en espacios geográficos y temporales concretos.

La investigación de Víctor Brangier tiene el mérito de otorgarle carnadura a dicho proyecto historiográfico, en el espacio concreto de la zona centro-sur de Chile entre los años 1824 y 1875. En 1824 se creó el Reglamento de Administración de Justicia, el cual fue un hito fundacional para la justicia republicana, combinando elementos del ordenamiento anterior con patrones de organización de nuevo cuño. Por su parte, en 1875 se promulgó la Ley de Organización y Atribución de Tribunales de 1875, que reformuló el esquema de administración judicial sostenido por el Reglamento mencionado. En este marco temporal, los saberes jurídico-judiciales se iban desplegando junto con la configuración del poder judicial chileno, y las prácticas estatales que éste auspiciaba. En las provincias de Maule y Colchagua la presencia de una justicia lega, próxima y vecinal permitía la construcción de saberes sociales.

La pesquisa se encarga de valorar e introducir y el diálogo del estudio con la historiografía sobre el Estado, la configuración de sus instituciones y la historia regional en el largo siglo XIX (Barriera, 2014: 36). A través de esta literatura, se descarta la idea de la justicia como un dispositivo efectivo de poder sobre la población, observando los ideales de la administración judicial a nivel local y los límites y discontinuidades de dichos procesos estatales. En vez de cumplir ciegamente los preceptos liberales, los magistrados privilegiaban la observación de prácticas y representaciones sociales a la hora de impartir justicia.

A través del concepto de "culturas jurídico-judiciales" el autor propone explorar los puntos de 
comunicación entre los saberes de los agentes judiciales y los de los sujetos sociales. Se trataba de un "sustrato simbólico y axiológico" que reflejaba las emotividades, las tácticas, los intereses y las expectativas puestas en el proceso legal. Estos eran los móviles que llevaban a recurrir a la justicia criminal de su territorio o a responder de cierta forma cuando se le exhortaba su participación. Las negociaciones y acuerdos producidos por unos y otros respondían a una variabilidad de conductas humanas que no necesariamente llevaba a que los sujetos actuaran de una manera considerada racional, sino que iban de la "vocación espontánea" a la "táctica calculada" por posicionarse de manera legítima frente al juez.

Vale rescatar la invocación a las culturas jurídico-judiciales en plural, teniendo en cuenta la creatividad cada sujeto social. El modo plural que el autor le otorga al concepto se ha debido a las transformaciones que experimentaron las concepciones a lo largo del período, observándose por un lado la yuxtaposición entre la herencia de una raíz moral y cristiana, y el ascenso de los nuevos bienes jurídicos liberales; y por otro lado la coexistencia de las antiguas instituciones legales, y el esquema de organización de juzgados $\mathrm{y}$ tribunales que se iba desplegando de manera performativa por el territorio. Las convivencias entre estas culturas jurídico-judiciales se hacen patente a lo largo de la investigación, tanto en el uso de valores y representaciones en las argumentaciones de los litigantes como de los agentes judiciales, como en las formas en las que se dibujaba la administración de justicia local. Las "figuras discursivas", "alegorías dicotómicas" e imágenes a las que apela el autor eran producidas por los actores históricos, quienes traducían los elementos jurídico-judiciales en construcciones que permitían obtener la legitimidad en las situaciones judiciales estudiadas.

El estudio responde a un relevo cuantioso de expedientes de justicia de paz, involucrando 411 procesos relativos a disputas interpersonales. Estos conflictos aparecen como pertinentes para ser estudiados, ya que se generaban en torno a las ideas e intereses relevantes para el período histórico como las propiedades, las honras y los propios cuerpos. A partir de este relevamiento, el autor ha escogido sutilmente los casos judiciales más representativos para ser narrados en los capítulos, entretejiendo en la trama discursiva las particularidades de los casos con las argumentaciones explicativas. Asimismo, se consultaron archivos relativos a las instituciones legales y estatales: diarios oficiales, memorias, cuerpos legales, anuarios estadísticos y censos. Ello permite a lo largo del estudio la confrontación de las experiencias judiciales con las expectativas y prácticas estatales.

La obra se divide en tres partes, cada una con su problemática interna, y al mismo tiempo sumando complejidad al análisis del "saber hacer y decir" en situación judicial. La primera se encarga de presentar el escenario geográfico en donde se explora la administración de justicia criminal. Allí se realiza una caracterización del perfil de los actores involucrados en los procesos. En relación a los jueces, el autor introduce las críticas de los contemporáneos sobre su carácter lego, la considerada necesidad introducir jueces letrados y la carencia de vecinos capaces de cumplir las 
funciones judiciales. El foco en los demás integrantes de los juzgados, como los defensores, secretarios de juzgado, representantes de los litigantes permite observar las fronteras permeables entre el juzgado y el ámbito social. Todo ello dibuja un escenario en donde se entrevén las grietas e intersticios que atravesaban la práctica cotidiana del ejercicio judicial.

A partir de un análisis cuantitativo sobre las filiaciones de los litigantes, se visualiza que la mayoría de las partes en conflicto se conocían y residían en el mismo espacio, siendo posible que intercambiasen acuerdos y negociaciones a partir de similares códigos, valores y representaciones. Así se observan las características de la justicia de proximidad, en la que medianos y pequeños propietarios, residentes en el lugar se enfrentaban también contra otros sujetos residentes. De esta manera, se demuestra que durante el medio siglo que ocupa esta pesquisa en el centro-sur de Chile, la justicia no puede ser pensada como un brazo del poder central para lograr la contención de los "sectores populares".

En la segunda parte del libro se estudian las culturas jurídicos-judiciales de los actores que protagonizaron los juicios, a partir de tres de sus aristas más visibles: los valores, las expectativas de alcanzar acuerdos y la opción del perdón. A partir de estas dimensiones, los actores sociales participantes de los procesos desplegaban sus sentidos sobre lo justo e injusto. Estos valores y bienes jurídicos expresaban tangiblemente los legados las culturas jurídicas hispanoamericanas heredadas del Antiguo Régimen y su resignificación en el quehacer judicial en el marco de las repúblicas en configuración como Chile.

Algunos de los valores que se exploran en esta segunda parte son: la apelación al bienestar material, la satisfacción de las necesidades materiales, la costumbre local, la honorabilidad y la obediencia al juzgado. Algunos bienes jurídicos como la patria potestad, la honra y la obediencia a la autoridad local eran apelados para expresar la transgresión por parte de una de las partes del juicio. La compasión por los culpables era otro de los elementos valorados por las culturas jurídico-judiciales del momento histórico, lo que implicaba el perdón por parte de los agentes judiciales. En relación a ello, la alegoría o figura de la "victima sufriente" resaltaba el daño recibido por la contraparte y apelaba a la conmiseración del juez sobre el castigo al ofensor.

La expectativa frente al valor de la paz y de los acuerdos queda demostrada en el relato de casos judiciales que intentaban la composición social por medio de la conciliación. Se da cuenta que, a pesar de las iniciativas por la aplicación rigurosa de las leyes penales y la persecución del crimen, ello no omitía la vigencia que cobraba el valor de los acuerdos entre partes. Sin embargo, vale tener en cuenta que los intentos de conciliación no siempre dieron sus frutos, debido a los intereses y las emociones de las partes en conflicto.

En la tercera parte del libro, se exploran los juicios por "torcida administración de justicia", los cuales develaron una inclinación a judicializar las situaciones a partir de los valores jurídicos del abuso del poder, del mal desempeño del 
cargo, y de la transgresión de la legalidad. Así, la figura jurídica del "buen juez”, caracterizada como ejecutor ciego de la ley, y agente separado de su hábitat social era utilizada por parte de los actores para realizar tramitaciones favorables a alguna de las partes del proceso. Los actores de la localidad se defendían ante lo que consideraban un acto arbitrario del juez residente que les perjudicaba. A su vez, mostraban un conocimiento de las distintas instancias que componía la red judicial, entreviendo cuál juez les resultaba más adecuado a sus intereses.

En su conjunto, se hace posible explorar el espacio judicial como un espacio de disputas y de acomodo de correlación de fuerzas sociales. Así, se visualiza uno de los móviles que llevó a los actores a judicializar los conflictos: las expectativas por mantener o mejorar su posición frente a las tensiones que atravesaban los vínculos. En ese sentido el concepto de "saber hacer y decir" ilustra los intereses y emociones producidas por los distintos actores, para quienes las relaciones de proximidad y de vecindad determinaban sus preocupaciones y posicionamientos. Se trataba de zonas de intersección que formaban parte de esas sociedades locales, en las que convergían los sujetos judicializados y los agentes de justicia (Caimari, 2007: 10).

La valoración de las relaciones locales no deja de ser observaba a través de los aportes de la historiografía hispanoamericana sobre la historia socialy de la justicia en el siglo XIX. Estas contribuciones permiten visualizar el sustrato cultural en el que se inserta la investigación. En este sentido, lejos de ser un mero "estudio de caso", la obra rebasa los límites regionales para colocar la experiencia del centro-sur de Chile en diálogo con los procesos continentales.

El esfuerzo por atravesar una perspectiva no lineal, procesual y situacional se hace patente en la lectura desde el comienzo hasta el final de la obra. Ello se concreta en la exploración del saber hacer y decir de los sujetos en situación judicial a través de los valores y bienes jurídicos que tenían disponibles en el sustrato social en el que se encontraban; la convivencia de culturas jurídicas-judiciales heredadas y resignificadas a la luz de la experiencia republicana; y los intersticios y discontinuidades que sobrellevaban las instituciones de administración judicial en los procesos de despliegue estatal.

Estas contribuciones allanan el camino para que futuras investigaciones se puedan ocupar de los sentidos sociales de lo justo y lo injusto en torno a temáticas como la raza, el género y la clase presentes en las sociedades del centro-sur de Chile del siglo XIX; las negociaciones y la construcción de saberes en otras instancias legales y estatales; la formación y configuración de las instituciones y agentes estatales chilenos; y del desarrollo del liberalismo en Chile. En conexión con la perspectiva epistemológica desarrollada en la obra, estos futuros estudios contribuirían al análisis de los límites del ejercicio del control social por parte de las instituciones estatales en formación, en conexión con el análisis de las experiencias compartidas de las sociedades históricas. 


\section{Referencias citadas}

Barriera, D. (2014): “La historia de la justicia y las otras historias”, en Richard-Jorba, R. y M. Bonaudo, coords., Historia regional. Enfoques y articulaciones para complejizar una historia nacional, La Plata, Edulp.

Caimari, L.,comp., (2007): La ley de los profanos. Delito, justicia y cultura en Buenos Aires (1870-1940), Buenos Aires, FCE.

Salvatore, R., Aguirre, C. y G. Joseph, eds., (2001): Crime and punishment in Latin America, Durham \& London, Duke University Press.

Florencia Castells

Doctoranda en Historia

Universidad Nacional de La Plata 